\title{
A case of multiple carcinoid
}

\section{tumors of the small intestine}
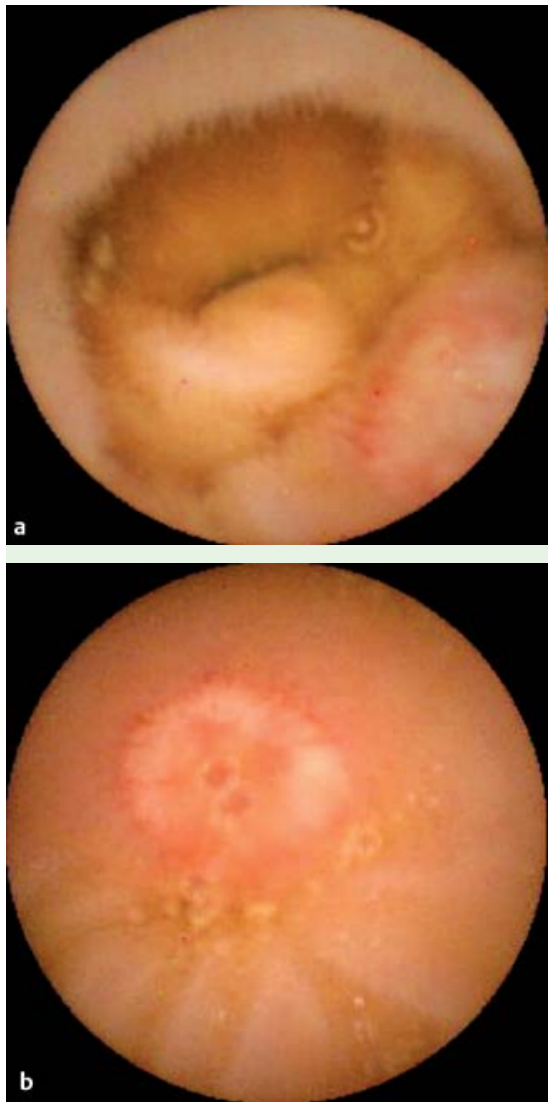

Fig. 1 a Capsule endoscopy showing smooth protrusions covered by normal-appearing mucosa. b Some of the tumors have a central depression on the top.

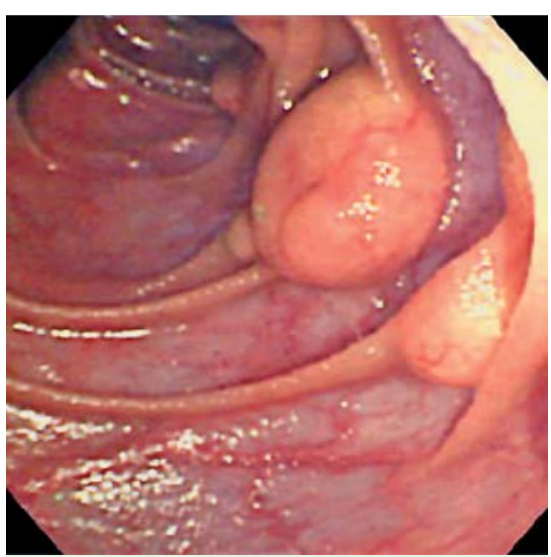

Fig. 2 Intraoperative enteroscopy showing multiple smooth protrusions.

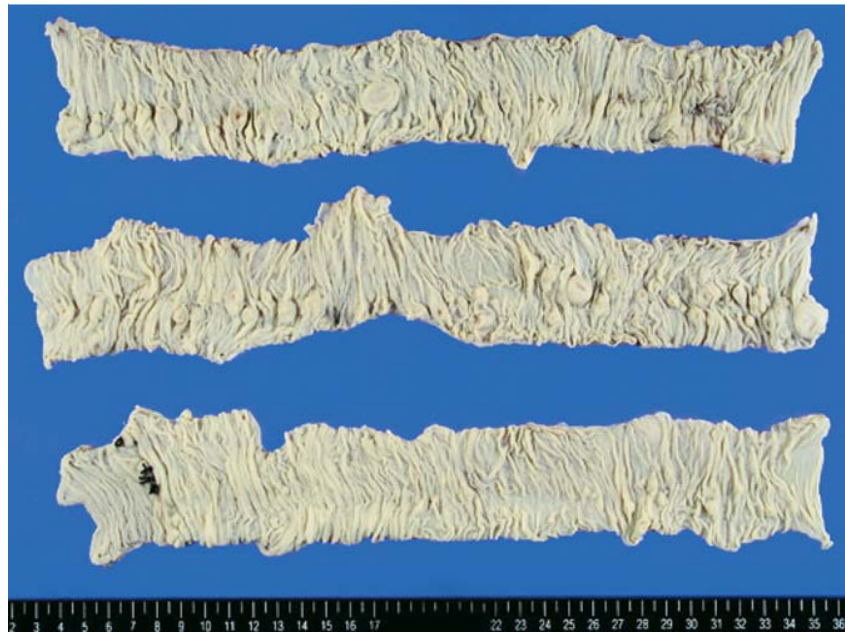

Fig. 3 Macroscopic examination of the resected segment of the small intestine. There were 111 protrusions ranging from $1 \mathrm{~mm}$ to $13 \mathrm{~mm}$ in size. The tumors had a smooth surface with an occasional ulcer in the center and were located predominantly in the antimesenteric surface of the intestine.

A 56-year-old man was referred to our institution with hematochezia and general fatigue. Esophagogastroduodenoscopy, total colonoscopy, and angiography failed to identify the source of bleeding. We then examined the patient with capsule endoscopy, which revealed multiple elevated lesions in the middle of the small intestine ( $\bullet$ Fig. 1). The tumors were yellowish in color and were covered with mucosa of normal appearance.

Intraoperative enteroscopy carried out during a laparotomy also revealed numerous protrusions ( Fig. 2). A $97-\mathrm{cm}$ segment of the middle part of the small intestine was resected. On macroscopic examination, 111 protrusions were noted in the resected segment ( Fig. 3 ). The size of the tumors ranged from $1 \mathrm{~mm}$ to $13 \mathrm{~mm}$. Microscopically, the tumors were composed of uniform cells, with a round to oval nucleus and eosinophilic cytoplasm, proliferating in a solid, trabecular, or glandular fashion. Two tumors had invaded the muscularis propria and the serosa ( Fig. 4). The patient has been metastasis-free for 4 years since the surgery.

Approximately $30 \%$ of carcinoid tumors of the small bowel occur as multiple tumors $[1,2]$. However, there have been few reports of more than 10 carcinoid tumors of the small intestine in one patient. Yantiss et al. [3] reported that patients with multiple carcinoid tumors were usually younger, had more frequent vascular invasion, and had a poorer prognosis than patients with a single tumor.

With the widespread use of capsule endoscopy and double-balloon endoscopy, enteroscopic findings of gastrointestinal polyposis have become clearer [4,5]. On the basis on our experience, we recommend considering multiple carcinoids as a possible diagnosis in patients with numerous polypoid lesions in the small intestine.

\section{Endoscopy_UCTN_Code_CCL_1AC_2AC}

\section{R. Yanaru-Fujisawa1, T. Matsumoto ${ }^{1}$, M. Esaki ${ }^{1}$, Y. Ohji ${ }^{2}$, M. Gushima ${ }^{2}$,}

M. Hirahashi' ${ }^{2}$ R. Mibu ${ }^{3}$, T. Yao ${ }^{4}$, M. lida ${ }^{1}$ 1 Department of Medicine and Clinical Science, Graduate School of Medical Sciences, Kyushu University, Fukuoka, Japan

2 Department of Anatomic Pathology, Graduate School of Medical Sciences, Kyushu University, Fukuoka, Japan

3 Department of Surgery and Oncology, Graduate School of Medical Sciences, Kyushu University, Fukuoka, Japan

4 Department of Human Pathology, Juntendo University School of Medicine, Tokyo, Japan 

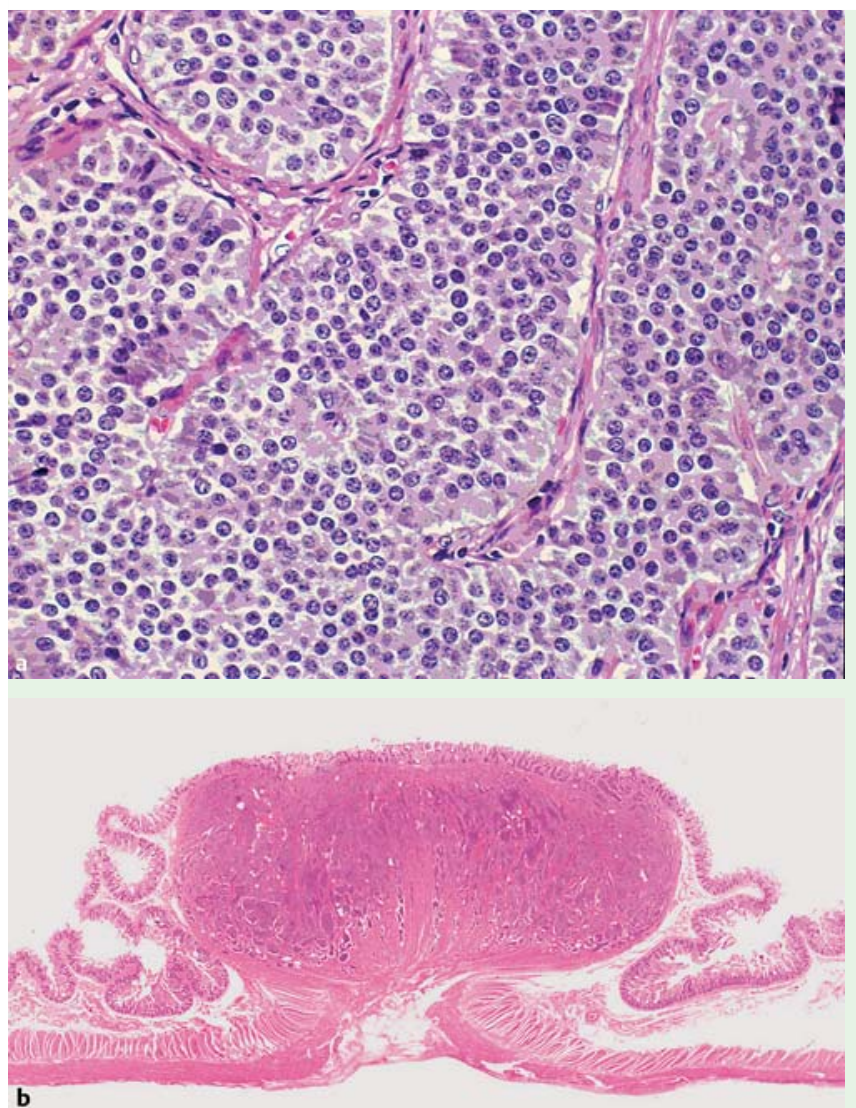

Fig. 4 a The tumor cells, showing a round or oval nucleus and eosinophilic cytoplasm, are arranged in a solid, trabecular, or glandular pattern.

b Microscopic section from the largest tumor showing that the tumor cells had invaded the muscularis propria.

\section{References}

1 Peck IJ, Shields AB, Boyden AM et al. Carcinoid tumors of the ileum. Am J Surg 1983; 146: $124-132$

2 Butkr AP, Thomas RM, Elsayed AM et al. Carcinoids of the jejunum and ileum. Cancer 1997; 79: 1086-1093

3 Yantiss RK, Odze RD, Farraye FA et al. Solitary versus multiple carcinoid tumors of the ileum. Am J Surg Pathol 2003; 27: 811 - 817

4 Cobrin GM, Pittman RH, Lewis BS. Increased diagnostic yield of small bowel tumors with capsule endoscopy. Cancer 2006; 107: 22 27

5 Yamamoto H, Kita H, Sunada K et al. Clinical outcomes of double-balloon endoscopy for the diagnosis and treatment of small-intestinal diseases. Clin Gastroenterol Hepatol 2004; 2: 1010 - 1016

\section{Bibliography}

DOI $10.1055 / \mathrm{s}-0029-1214985$

Endoscopy 2009; 41: E299-E300

(c) Georg Thieme Verlag KG Stuttgart · New York . ISSN 0013-726X

\section{Corresponding author \\ R. Yanaru-Fujisawa}

Department of Medicine and Clinical Science Graduate School of Medical Sciences Kyushu University

Maidashi 3-1-1

Higashi-ku

Fukuoka 812-8582

Japan

Fax: +81-92-642-5273

yritsuko@intmed2.med.kyushu-u.ac.jp 